\title{
The Gaze Communications Between Dogs/Cats and Humans: Recent Research Review and Future Directions
}

\author{
Hikari Koyasu',2, Takefumi Kikusui ${ }^{1}$, Saho Takagi, ${ }^{1,2}$ and Miho Nagasawa ${ }^{1 *}$ \\ ${ }^{1}$ Laboratory of Human-Animal Interaction and Reciprocity, Azabu University, Kanagawa, Japan, ${ }^{2}$ Japan Society \\ for the Promotion of Science, Tokyo, Japan
}

\section{OPEN ACCESS}

Edited by:

Christian Nawroth,

Leibniz Institute for Farm Animal

Biology (FBN), Germany

Reviewed by:

Debottam Bhattacharjee, Utrecht University, Netherlands

Federica Amici,

Max Planck Institute for Evolutionary

Anthropology, Germany

${ }^{*}$ Correspondence:

Miho Nagasawa

nagasawa@carazabu.com

Specialty section:

This article was submitted to

Comparative Psychology,

a section of the journal

Frontiers in Psychology

Received: 02 October 2020 Accepted: 30 November 2020 Published: 18 December 2020

Citation:

Koyasu H, Kikusui T, Takagi S and

Nagasawa M (2020) The Gaze

Communications Between Dogs/Cats and Humans: Recent Research

Review and Future Directions.

Front. Psychol. 11:613512.

doi: 10.3389/fpsyg.2020.613512
Dogs (Canis familiaris) and cats (Felis silvestris catus) have been domesticated through different processes. Dogs were the first domesticated animals, cooperating with humans by hunting and guarding. In contrast, cats were domesticated as predators of rodents and lived near human habitations when humans began to settle and farm. Although the domestication of dogs followed a different path from that of cats, and they have ancestors of a different nature, both have been broadly integrated into-and profoundly impacted-human society. The coexistence between dogs/cats and humans is based on non-verbal communication. This review focuses on "gaze," which is an important signal for humans and describes the communicative function of dogs' and cats' eyegaze behavior with humans. We discuss how the function of the gaze goes beyond communication to mutual emotional connection, namely "bond" formation. Finally, we present a research approach to multimodal interactions between dogs/cats and humans that participate in communication and bond formation.

Keywords: dogs, cats, humans, gaze, interaction, communication, bond

\section{DOMESTICATION OF DOGS AND CATS}

Dogs (Canis familiaris) and cats (Felis silvestris catus) are the closest animals living with humans. Dogs, domesticated approximately 15,000 years ago, were the first animals domesticated from wild species (Freedman and Wayne, 2017). They acquired social tolerance to humans and cooperated with humans by assisting in hunting and guarding. Dogs were first selected because of their reduced stress response to humans, and then for the usefulness of their cooperation with humans (Driscoll et al., 2009). Wolves (Canis lupus), sharing a common ancestor with dogs, have developed a greater ability to cooperate than dogs, but wolves only display intra-specific cooperation. In contrast, cats were domesticated approximately 10,000 years ago, primarily because they were predators whose prey included rodents (Vigne et al., 2004). Additionally, cats were not artificially selectively bred. The cat's ancestor is the wildcat (Felis silvestris lybica), a solitary, territorial animal, like most other Felidae (Bradshaw, 2016).

Although dogs have ancestors with a different nature than cats, and were domesticated via different processes, they are the most common animals living with humans (Figure 1). The foundation of this coexistence is non-verbal communication. They use their sense of smell, hearing, touch, and eyesight to communicate with humans. Dogs and cats are sensitive to gaze, which humans use as a form of non-verbal communication. In this review, we introduce the communicative function of gaze in dog-human and cat-human interactions in recent studies (Table 1). Second, we describe bond formation beyond communication and the importance of gaze 
in bond formation. Finally, we discuss the possibility that other senses contributed to the bonds formed between dogs/cats and humans and a research approach to the multimodal interactions that facilitate communication and bond formation. Comparing the ways dogs and cats interact with humans provides insight into how both species have integrated into human society. In other words, the differences between dogs and cats may have originated due to differences in their ancestral species' social natures and the process of domestication. The similarities between dogs and cats may also be due to changes in their cognitive function that allowed them to integrate into human society. With these considerations in mind, we review the findings to date.

\section{GAZE COMMUNICATION FOR DOGS}

It is easy to determine the direction of gaze of wolves that hunt cooperatively in packs because of the type of eyes they have. Furthermore, wolves have developed behaviors for receiving and sending their gaze signals (Ueda et al., 2014). These results suggest that wolves use gaze to communicate with others. It is possible that dog's ancestors inherited this function and dogs have applied it as gaze-based communication in their interactions with humans.

When dogs receive human gaze, they change their behavior depending on its direction. For example, dogs were given a series of trials in which they were forbidden to consume any visible food (Call et al., 2003; Kaminski et al., 2013). When the human looked at them, dogs retrieved food less often than in the conditions in which humans did not look at them. Additionally, dogs were more obedient to their owners' commands when their owners looked at them (Schwab and Huber, 2006). Dogs detect a human's attentional state from the direction of their gaze. This behavior is necessary for dogs' ability to respond to human commands, such as when hunting. Furthermore, dogs expect what humans can see and change their behavior accordingly. For example, in an experiment, two toys were placed in a room, one was blocked by opaque panels to prevent humans from seeing it. Although the dogs could see both toys, when ordered to "fetch," they picked the one visible to the humans (Call et al., 2003). In another experiment observing the free behaviors of dogs, the duration of their attention-getting behaviors (e.g., whining, whimpering, and looking at owners' faces) was longer in response to their owner's gaze (Ohkita et al., 2016). This ability to recognize other's perspectives could be beneficial to humans' and dogs' cooperative hunting.

Dogs are more likely to select food from humans who are looking at them than those who are not (Gácsi et al., 2004); this tendency was likely to have been acquired early in the domestication process. Dogs often exhibit more hesitative behaviors when approaching a blindfolded human but beg for food from a human with visible eyes (Gácsi et al., 2004). This difference indicates that, based on gaze, dogs may distinguish between humans who are willing to give food and those who are not, and they receive food from the former when they are allowed to consume. Food, and knowing if someone would give them food, was a significant factor in dogs' early domestication.
Dogs use human signals such as pointing (Miklosi et al., 2005) and gazing accompanied by pointing even when they are puppies (Hare et al., 2002). One study showed that dogs were easily able to use human pointing to select one of two containers in which food was hidden using human pointing and gaze direction. In contrast, chimpanzees, close relatives of humans, find it difficult to use human cues in this task. Furthermore, a dog's gaze follows only a human gaze (Hare et al., 1998; Agnetta et al., 2000; Téglás et al., 2012; Met et al., 2014). They look in the direction in which the human gaze (with head movements) is directed. Dogs follow not only the gaze but also the movements of humans. When there were two bowls with food, dogs followed the one that more humans went to under certain conditions (Nagasawa et al., 2020). Dogs chose the same container they had seen humans choose, even if they had seen the human removing food from it and pretending to eat it (Chijiiwa et al., 2020). Following human behaviors, including gaze, would have helped dogshuman cooperation for hunting and gathering before humans began establishing cultures based on cultivation and settlements.

Dogs exhibit social referencing by looking at and using facial expressions and behaviors of others in unfamiliar situations. In unsolvable tasks in which they cannot access food, they look at their owners (Miklosi et al., 2005), but see Lazzaroni et al. (2020). Even when they encounter a strange object, a fan with some ribbons, most dogs look referentially to their owners after looking at the strange object (Merola et al., 2012a,b). This alternating gaze is thought to have the function of joint attention, directing others' gaze to an object to garner problem-solving cooperation. In humans, alternating gaze followed by joint attention is thought to be related to identifying intention and establishing reference (Emery, 2000). Dogs can also use their own gaze to guide a human's gaze. Although the function of dogs' alternating gaze from objects to humans is unclear, dogs may rely on humans to help them in situations where they did not know what to do or cannot solve problems themselves.

Recent research suggests that dogs' gazing behaviors with humans are influenced by the dogs' life experiences (Marshall-Pescini et al., 2017; Brubaker et al., 2019). Hence, both domestication and socialization influence a dogs' gaze behavior with humans.

\section{GAZE COMMUNICATION FOR CATS}

The ancestors of cats lived alone; therefore, they may not have needed the ability to read the gaze of other individuals as much as species that hunted in groups. However, there are some recent reports of communication through gaze between cats and humans.

Cats detect human gaze with head movements and accordingly change their behavior (Koyasu and Nagasawa, 2019). When a familiar human (i.e., experimenter) and a cat spent time in the same room, the cat's behavior was observed in response to the familiar human's gaze. Cats looked at a familiar human for a shorter duration when the cats were directed gaze than when the cats were not, suggesting that, unlike dogs, they exhibit the behavior of avoiding a familiar gaze. Cats may see a human gaze 


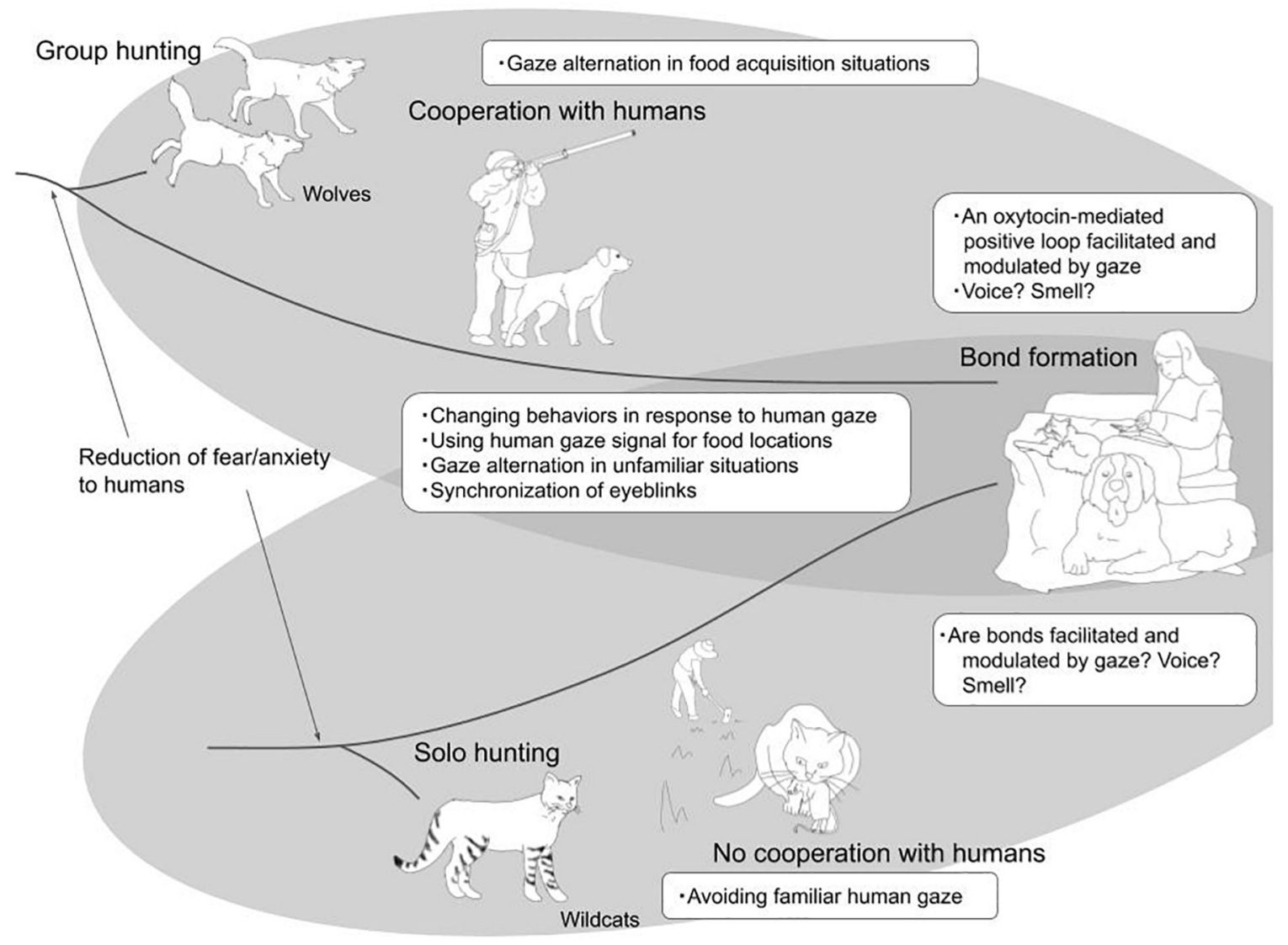

FIGURE 1 | Domestication of dogs and cats and gaze communication with humans. Although dogs and cats have ancestors with a different nature, they have started living with humans, using nonverbal communication, especially gaze. The similar gaze communications observed in both dogs and cats were shown in the overlap of two circles. Using non-verbal communicative signals they can form bonds with humans.

as the same thing as a cat's gaze, which indicates a threat in a social situation with no goal or threat (Bradshaw, 2016).

However, in a study with feeding situations, cats were fed by humans who gazed at them (Ito et al., 2016). As with Gácsi et al. (2004), two humans performed differently in front of cats. Cats selected more food from humans who called their names with gazing than food from humans who called their names without gazing. Whether or not cats avoid/select gaze may depend on the experimental situation. Cats also use human signals (Miklosi et al., 2005). Regarding the ability to use human pointing, no statistically significant performance has been found between dogs and cats.

Furthermore, cats can follow a human's gaze (Pongrácz et al., 2019). In a two-way food selection situation, cats followed a human gaze (with a head movement) in about $70 \%$ of the trials. In the condition for selecting one of two food bowls, cats also followed the movements of humans, not just their gaze. As with dogs, cats visited the container following humans, even after seeing the human removing food and pretending to eat it (Chijiiwa et al., 2020). As cats became a part of human society to catch mice but were not required to serve any other role, they may have acquired these abilities in their development because of their dependence on humans for food today. These similarities between dogs and cats indicate they are both easily affected by human behaviors in situations involving food, despite the two species' different domestication histories.

Cats did not exhibit social reference behavior in the unsolvable task in a feeding situation, unlike dogs (Miklosi et al., 2005). Cats may use the cues provided but not demand cues themselves. Because they did not rely on others for food, they do not demand cues themselves. However, depending on the situation, cats do exhibit social reference (Merola et al., 2015). When cats were shown the fan with some ribbons, $80 \%$ alternated their gaze between the fan and their owner, but their behaviors changed based on the human's emotional expression. When cats encounter strange objects and do not know what to do, they can read the human's facial expression/behavior or lead the human gaze to objects. Considering the process of domestication, these results may be due to cats' lack of a history of cooperating with humans to acquire food.

Thus, cats avoid/select the gaze and exhibit/do not exhibit social references depending on the social context. Investigating the contexts in which they require a human gaze may clarify the factors that facilitate the acquisition of humanlike communication skills, but cats undoubtedly use gaze to communicate with humans. It is considered to have evolved through life with humans, although the gaze function originally was not necessary for cats. 
TABLE 1 | Gaze communication between dogs/cats and humans.

\begin{tabular}{|c|c|c|c|}
\hline Dogs & References & Cats & References \\
\hline \multicolumn{4}{|l|}{ Response to human gaze } \\
\hline Stole food less often & Call et al., 2003; Kaminski et al., 2013 & Avoided the gaze of familiar human & Koyasu and Nagasawa, 2019 \\
\hline $\begin{array}{l}\text { Obeyed more commands of their } \\
\text { owners }\end{array}$ & Schwab and Huber, 2006 & $\begin{array}{l}\text { Selected food from humans who looked at } \\
\text { them }\end{array}$ & Ito et al., 2016 \\
\hline $\begin{array}{l}\text { Fetched the toy that humans } \\
\text { could see in the situation with } \\
\text { two toys }\end{array}$ & Call et al., 2003 & & \\
\hline $\begin{array}{l}\text { Increased attention-getting } \\
\text { behaviors }\end{array}$ & Ohkita et al., 2016 & & \\
\hline $\begin{array}{l}\text { Selected food from humans who } \\
\text { looked at them }\end{array}$ & Gácsi et al., 2004 & & \\
\hline \multicolumn{4}{|l|}{ Using human signals } \\
\hline $\begin{array}{l}\text { Used human pointing in the task } \\
\text { of selecting one of two } \\
\text { containers }\end{array}$ & Miklosi et al., 2005 & $\begin{array}{l}\text { Used human pointing in the task of } \\
\text { selecting one of two containers }\end{array}$ & Miklosi et al., 2005 \\
\hline $\begin{array}{l}\text { Used human gaze direction with } \\
\text { pointing in the task of selecting } \\
\text { one of two containers }\end{array}$ & Hare et al., 2002 & $\begin{array}{l}\text { Looked in the direction indicated by } \\
\text { human gaze (with head movements) }\end{array}$ & Pongrácz et al., 2019 \\
\hline $\begin{array}{l}\text { Looked in the direction directed } \\
\text { by human gaze (with head } \\
\text { movements) }\end{array}$ & $\begin{array}{l}\text { Hare et al., 1998; Agnetta et al., 2000; } \\
\text { Téglás et al., 2012; Met et al., } 2014\end{array}$ & $\begin{array}{l}\text { Followed the container that humans visited } \\
\text { in a situation with two food containers }\end{array}$ & Chijiiwa et al., 2020 \\
\hline $\begin{array}{l}\text { Followed the container that } \\
\text { humans visited in a situation with } \\
\text { two food containers }\end{array}$ & $\begin{array}{l}\text { Chijiiwa et al., 2020; Nagasawa et al., } \\
2020\end{array}$ & & \\
\hline \multicolumn{4}{|l|}{ Social reference } \\
\hline $\begin{array}{l}\text { Looked alternately at the food } \\
\text { and the owner when it could } \\
\text { access the food }\end{array}$ & Miklosi et al., 2005, Lazzaroni et al., 2020 & $\begin{array}{l}\text { Did not look alternately at the food and the } \\
\text { owner when it could not access the food }\end{array}$ & Miklosi et al., 2005 \\
\hline $\begin{array}{l}\text { Looked alternately at the strange } \\
\text { object and the owner }\end{array}$ & Merola et al., 2012a,b & $\begin{array}{l}\text { Looked alternately at the strange object } \\
\text { and the owner }\end{array}$ & Merola et al., 2015 \\
\hline \multicolumn{4}{|c|}{ The role of gaze in bond formation } \\
\hline $\begin{array}{l}\text { Increased attention-getting } \\
\text { behaviors in dogs, which } \\
\text { function as attachment behaviors } \\
\text { in response to human gaze }\end{array}$ & Ohkita et al., 2016 & $\begin{array}{l}\text { Eyeblink synchronization during mutual } \\
\text { gazing }\end{array}$ & Koyasu et al., 2020 \\
\hline $\begin{array}{l}\text { Dog owner's oxytocin secretion } \\
\text { increased in response to the } \\
\text { dog's gaze }\end{array}$ & Nagasawa et al., 2009 & & \\
\hline $\begin{array}{l}\text { An oxytocin-mediated positive } \\
\text { loop of bond formation facilitated } \\
\text { and modulated by gazing, like } \\
\text { mother-infant }\end{array}$ & Nagasawa et al., 2015 & & \\
\hline $\begin{array}{l}\text { Eyeblink synchronization during } \\
\text { mutual gazing }\end{array}$ & Koyasu et al., 2020 & & \\
\hline
\end{tabular}

\section{BOND FORMATION BETWEEN DOGS/CATS AND HUMANS}

Dogs/cats can distinguish between signals based on human emotions. Dogs change their behavior depending on the emotional state of humans. In one study, dogs sniffed, nuzzled, and licked a human who was pretending to cry (Custance and Mayer, 2012). In the social referencing experiment described above, dogs approached the strange fan when their owners reacted positively and moved away from it when their owners reacted negatively (Merola et al., 2012b). Dogs also distinguished between emotional states and facial expressions of humans (Nagasawa et al., 2011; Buttelmann and Tomasello, 2013; Turcsán et al., 2015). Likewise, cats change their behavior depending on the human emotional state. When an owner was depressed, the cat rubbed against their owner more often (Rieger and Turner, 1999). A study showed that a cat's behavior toward its owner during interactions was affected by their owner's emotional state (Turner and Rieger, 2001). As with dogs, they distinguished between humans' facial expressions and associated postures (Merola et al., 2015; Galvan and Vonk, 2016) and strangers' voices (Quaranta et al., 2020). Dogs/cats can distinguish between signals 
based on human emotions, which would be the foundation for forming emotional bonds.

Previous studies also suggest that emotional bonds exist between dogs/cats and humans. To examine whether an emotional bond is formed, it is necessary to know if animals show 1) an emotional or behavioral response to specific individuals and 2) a stress response to separation and a stress reduction/pleasurable behavior in reunions (DeVries, 2002). The Ainsworth Strange Situation Test (SST) has been widely used to demonstrate infants', dogs', and cats' bonds to their primary caretakers.

In novel environments, dogs' exploring and playing behaviors increased when there was an owner in the room compared to when there was only a stranger in the room, and their following behavior increased when the owner left the room compared to when the stranger left the room (Topal et al., 1998). This observation means that dogs behave differently toward their owners than strangers; their owners function as a secure base, like the human mother-infant bond.

In the formation of these human-dog bonds, gaze plays an important role. In experiments observing the free behaviors of dogs in response to human gaze, dogs' attention-gaining behaviors increased when owners looked at them (Hare et al., 2002). Dogs' increased attention-seeking when receiving a human gaze may be an attachment signal to draw their owners to them. Furthermore, the dogs' gaze directed at their owners led to increased oxytocin secretion in their owners (Nagasawa et al., 2009). The oxytocin neuroendocrine system is associated with uterine contraction during childbirth and the promotion of breast milk secretion and plays an important role in maternal behaviors following birth (Nagasawa et al., 2012). A dog's gaze increased the owner's interaction with the dog, which increased oxytocin secretion in dogs; in other words, there is an oxytocin-mediated positive loop of bond formation facilitated and modulated by gazing in human-dogs, like mother-infants (Nagasawa et al., 2015).

Cat-owner bonds are a form of attachment similar to that between dogs or infants and their caretakers (Edwards et al., 2007). In the SST, cats have been shown to spend more time engaged in locomotion/exploration when accompanied by their owners and exhibited higher alert behavior event frequency when accompanied by strangers. In a study reexamining these bonds using a crossover design experiment with an improved and counterbalanced modification of the SST, cats vocalized more when owners left the room than when strangers left (but there was no other evidence of a secure base) (Potter and Mills, 2015). Recently, a secure base test (SBT) was conducted to investigate whether humans function as an attachment figure for cats (Nagasawa et al., 2009). The cat-human bond was found to be similar to mother-infant and dog-human bonds; however, additional experimentation with strangers is required due to the lack of evidence that the bond was to a specific individual. There was proximity seeking, separation distress, and reunion behavior, which are indicators of attachment relationships between cats and caretakers. As shown, there is some evidence that there are cathuman bonds. However, it is unclear whether gaze facilitates the bond formation, as in a dog-human relationship. Since cats also communicate through gaze, especially with humans, gaze may be an important factor in bond formation.

Eyeblink, an unconscious signal, may also play a role in the mutual gaze that facilitates bond formation. A study reported that during mutual gaze, eyeblinks were synchronized between dogs and humans (Koyasu et al., 2020). Dogs blinked about one second after their owner or a stranger blinked. The owners blinked immediately after the dogs had blinked, and the strangers blinked after some delay following the dogs' blinks. Although there was some time lag, the presence of mutual blink synchronization was suggested. The same phenomenon was observed in cats. This synchronization is considered to lead to a mutual understanding and effective communication in humans. Synchronizing and obtaining the same physiological state as others may also lead to mutual understanding and effective communication in dogs and cats.

These results suggest that a similar communication signal evolved in humans, dogs, and cats. However, individual differences-specifically in personalities-exist. As dogs/cats and humans spend time together in a house, they can learn communications unique to the pair/group and probably form bonds with specific individuals. The bonds would be more beneficial for dogs and cats in terms of leading to more food, better food, and greater safety, and more beneficial for humans in terms of being less stressed, less anxious, and healthier. Therefore, interspecific bonding benefits both parties.

\section{VOICES AND SMELL THAT MAY CONTRIBUTE TO BOND FORMATION}

Since dogs and cats discriminate between humans using integrated different types of senses, other senses, such as auditory and olfactory, may also contribute to bond formation. Along with visual information, other forms of perceptual information may promote bond formation. Cats have adapted their voices to communicate more effectively with humans. For example, adult cats meow at humans (Mertens and Turner, 1988), but otherwise, meowing is generally only used for communication between kittens and their mothers (Bradshaw and CameronBeaumont, 2000). Additionally, domestic cats' meows are more comforting to humans than those of wildcats (Nicastro, 2004), and feral cats' meows are different from house cats' in acoustic variables indicated by a spectrogram (Yeon et al., 2011). Another example is that cats purr more when they are reunited with their owners after a long separation (Eriksson et al., 2017). Purring is a general sign of contentment or care soliciting behavior (McComb et al., 2009). Although purring can occur in different contexts (Merola and Mills, 2016), it is most commonly seen in kittens to solicit care from mothers (Bradshaw and Cameron-Beaumont, 2000). It is considered that domestication and socialization have led to the development of a cat's vocal communication with humans. Cats are also sensitive to human vocalizations. Cats distinguish between the voices of their owners and strangers (Saito and Shinozuka, 2013). Cats participating in a habituationdishabituation test showed a decreasing response when strangers' voices continued and increasing head and ear movements when 
hearing their owner's voice. Dogs also distinguish the voices of their owners (Adachi et al., 2007) and read human emotions through voice and intonation (Andics et al., 2016).

Cats also have highly developed communication through smell. Most small felids, including Felis silvestris lybica, the ancestor of cats, have exclusive territories. Species with large territories rarely encounter others and tend to communicate through smell. Some cats live in multi-cat households and high-density urban environments. Cats living in groups may distinguish between individuals who are group members and non-group members through smell. Cross infection between individuals during allorubbing or while marking communal scent posts would increase any similarity of smell profiles among the members of a social group, but that is not conclusively demonstrated (Gittleman, 2013). Thus, communication through smell in cats may be more complex than in other felids. They also communicate with humans through smell, as they exhibit rubbing behavior. The connection between their rubbing and social bonding is supported by the fact that cats are adept at communicating through smell. Smell helps dogs distinguish between their owners and strangers. The caudate nucleus region of dogs' brains is more strongly activated when exposed to familiar human smell compared to the smell of familiar dogs, unfamiliar dogs, unfamiliar humans, and their own smell, suggesting a positive emotional response to familiar human smell (Berns et al., 2015). Dogs may also distinguish human emotions by smell. Dogs showed higher cardiac activation when sniffing human fear chemosignals than when neutral (Siniscalchi et al., 2016). Dogs also show a similar emotional response to others through smell (D'Aniello et al., 2018) and behave accordingly.

Furthermore, dogs and cats generate visual images when they hear vocalizations (Adachi et al., 2007; Takagi et al., 2019). Such interchanges of information across sensory modalities may be useful to animals because the available modalities may be unavailable at other times. Additionally, individuals are identified through several senses, such as appearance, voice, and smell. The contribution of auditory and olfactory communication to bond formation will need to be investigated in future studies.

\section{CONCLUSION}

Dogs and cats have both been integrated into human habits for improved access to food, and they use human signals to

\section{REFERENCES}

Adachi, I., Kuwahata, H., and Fujita, K. (2007). Dogs recall their owner's face upon hearing the owner's voice. Anim. Cogn. 10:17. doi: 10.1007/s10071-006-0025-8

Agnetta, B., Hare, B., and Tomasello, M. (2000). Cues to food location that domestic dogs (Canis familiaris) of different ages do and do not use. Anim. Cogn. 3, 107-112. doi: 10.1007/s100710000070

Andics, A., Gábor, A., Gácsi, M., Faragó, T., Szabó, D., and Miklósi, A. (2016). Neural mechanisms for lexical processing in dogs. Science 353:1030. doi: 10 . 1126/science.aaf3777

Berns, G. S., Brooks, A. M., and Spivak, M. (2015). Scent of the familiar: an fMRI study of canine brain responses to familiar and unfamiliar human and dog odors. Behav. Process. 110:37. doi: 10.1016/j.beproc.2014.02.011 obtain information such as the location of food. However, they differ in their food acquisition situations. Dogs exhibit behaviors that require human cooperation while cats do not rely on humans, perhaps due to the nature of their ancestral species. Dogs first cooperated with humans as working animals, and cats were allowed in the human habitat to catch mice. However, today cats and dogs share an equal and similar ecological niche among humans.

It is particularly interesting that cats, originally solitary animals, can adapt to living in groups with humans and other cats. Most of the behaviors that cats exhibit toward humans were initially observed in mothers-kittens, suggesting that the behaviors seen in their adaptation to a group with humans were inherent. In the future, cats may acquire more dog-like abilities, such as more consistent and expressive gaze, through human selection. Investigating changes that cats may exhibit by selection would be helpful for understanding the evolutionary process of sociality in a broader context.

Dogs and cats use several senses to communicate with humans. Each of these senses contributes to the distinction between owner and stranger. Voices, smell, and other factors also foster the formation of bonds between dogs/cats and humans, and future research should investigate other perceptions that similarly may have been involved in the formation of bonds. The literature at present indicates that dogs and cats have their own adaptive communications that may have provided the basis for their mutually beneficial coexistence with humans.

\section{AUTHOR CONTRIBUTIONS}

HK, TK, ST, and MN wrote the manuscript. All authors contributed to the article and approved the submitted version.

\section{FUNDING}

This work was supported by the Japan Society for the Promotion of Science, and Grants-in-Aid for Scientific Research from the Ministry of Education, Culture, Sports, Science, and Technology of Japan (\#20J14760 to HK, \#19H00972 to TK, \#17J08974 to ST, and \#18H02489 and \#19K22823 to MN).

Bradshaw, J., and Cameron-Beaumont, C. (2000). "The signalling repertoire of the domestic cat and its undomesticated relatives," in The Domestic Cat: The Biology of its Behaviour, eds D. C. Turner and P. Bateson (Cambridge: Cambridge University Press), 67-93.

Bradshaw, J. W. S. (2016). Sociality in cats: a comparative review. J. Vet. Behav. 11, 113-124. doi: 10.1016/j.jveb.2015.09.004

Brubaker, L., Bhattacharjee, D., Ghaste, P., Babu, D., Shit, P., and Bhadra, A. (2019). The effects of human attentional state on canine gazing behaviour: a comparison of free-ranging, shelter, and pet dogs. Anim. Cogn. 22:1129. doi: 10.1007/s10071-019-01305-x

Buttelmann, D., and Tomasello, M. (2013). Can domestic dogs (Canis familiaris) use referential emotional expressions to locate hidden food? Anim Cogn 16, 137-145. doi: 10.1007/s10071-0120560-4 
Call, J., Bräuer, J., Kaminski, J., and Tomasello, M. (2003). Domestic dogs (Canis familiaris) are sensitive to the attentional state of humans. J. Comp. Psychol. 117:257. doi: 10.1037/0735-7036.117.3.257

Chijiiwa, H., Takagi, S., Arahori, M., Hori, Y., Saito, A., and Kuroshima, H. (2020). Dogs and cats prioritize human action: choosing a now-empty instead of a stillbaited container. Anim. Cogn. doi: 10.1007/s10071-020-01416-w [Epub ahead of print].

Custance, D., and Mayer, J. (2012). Empathic-like responding by domestic dogs (Canis familiaris) to distress in humans: an exploratory study. Anim. Cogn. 15:851. doi: 10.1007/s10071-012-0510-1

D'Aniello, B., Semin, G. R., Alterisio, A., Aria, M., and Scandurra, A. (2018). Interspecies transmission of emotional information via chemosignals: from humans to dogs (Canis lupus familiaris). Anim. Cogn. 21:67. doi: 10.1007/ s10071-017-1139-x

DeVries, A. C. (2002). Interaction among social environment, the hypothalamicpituitary-adrenal axis, and behavior. Horm. Behav. 41:405. doi: 10.1006/hbeh. 2002.1780

Driscoll, C. A., Macdonald, D. W., and O'Brien, S. (2009). From wild animals to domestic pets, an evolutionary view of domestication. Proc. Natl. Acad. Sci. U.S.A. 106(Suppl. 1), 9971-9978. doi: $10.1073 /$ pnas.0901586106

Edwards, C., Heiblum, M., Tejeda, A., and Galindo, F. (2007). Experimental evaluation of attachment behaviors in owned cats. J. Vet. Behav. 2, 119-125. doi: 10.1016/j.jveb.2007.06.004

Emery, N. J. (2000). The eyes have it: the neuroethology, function and evolution of social gaze. Neurosci. Biobehav. Rev. 24, 581-604. doi: 10.1016/s0149-7634(00) 00025-7

Eriksson, M., Keeling, L. J., and Rehn, T. (2017). Cats and owners interact more with each other after a longer duration of separation. PLoS One 12:e0185599.doi: 10.1371/journal.pone.0185599

Freedman, A. H., and Wayne, R. K. (2017). Deciphering the origin of dogs: from fossils to genomes. Annu. Rev. Anim. Biosci. 5, 281-307. doi: 10.1146/annurevanimal-022114-110937

Gácsi, M., Miklósi, A., Varga, O., Topál, J., and Csányi, V. (2004). Are readers of our face readers of our minds? Dogs (Canis familiaris) show situation-dependent recognition of human's attention. Anim. Cogn. 7:144. doi: 10.1007/s10071-0030205-8

Galvan, M., and Vonk, J. (2016). Man's other best friend: domestic cats (F. silvestris catus) and their discrimination of human emotion cues. Anim. Cogn. 19, 193-205. doi: 10.1007/s10071-015-0927-4

Gittleman, J. L. (2013). Carnivore Behavior, Ecology, and Evolution. Berlin: Springer Science \& Business Media.

Hare, B., Brown, M., Williamson, C., and Tomasello, M. (2002). The domestication of social cognition in dogs. Science 298, 1634-1636. doi: 10.1126/science. 1072702

Hare, B., Call, J., and Tomasello, M. (1998). Communication of food location between human and dog (Canis familiaris). Evol. Commun. 2, 137-159. doi: 10.1075/eoc.2.1.06har

Ito, Y., Watanabe, A., Takagi, S., Arahori, M., and Saito, A. (2016). Cats beg for food from the human who looks at and calls to them: ability to understand humans'attentional states. Psychologia 59, 112-120. doi: 10.2117 psysoc.2016.112

Kaminski, J., Pitsch, A., and Tomasello, M. (2013). Dogs steal in the dark. Anim. Cogn. 16:385. doi: 10.1007/s10071-012-0579-6

Koyasu, H., Goto, R., Takagi, S., Nakano, T., Nagasawa, M., and Kikusui, T. (2020). "Mutual synchronization of eyeblinks between dogs/cats and humans," in Proceedings of the 80th Annual Meeting of the Japanese Society for Animal Psychology, Suita.

Koyasu, H., and Nagasawa, M. (2019). Recognition of directed-gaze from humans in cats. Jpn. J. Anim. Psychol. 69, 2-3.

Lazzaroni, M., Marshall-Pescini, S., Manzenreiter, H., Gosch, S., Pøibilová, L., and Darc, L. (2020). Why do dogs look back at the human in an impossible task? Looking back behaviour may be over-interpreted. Anim. Cogn. 23:427. doi: 10.1007/s10071-020-01345-8

Marshall-Pescini, S., Rao, A., Virányi, Z., and Range, F. (2017). The role of domestication and experience in "looking back"towards humans in an unsolvable task. Sci. Rep. 7:46636.
McComb, K., Taylor, A. M., Wilson, C., and Charlton, B. D. (2009). The cry embedded within the purr. Curr. Biol. 19:R507.

Merola, I., Lazzaroni, M., Marshall-Pescini, S., and Prato-Previde, E. (2015). Social referencing and cat-human communication. Anim. Cogn. 18, 639-648. doi: 10.1007/s10071-014-0832-2

Merola, I., and Mills, D. S. (2016). Behavioural signs of pain in cats: an expert consensus. PLoS One 11:e0150040. doi: 10.1371/journal.pone.0150040

Merola, I., Prato-Previde, E., and Marshall-Pescini, S. (2012a). Dogs' social referencing towards owners and strangers. PLoS One 7:e47653.doi: 10.1371/ journal.pone. 0047653

Merola, I., Prato-Previde, E., and Marshall-Pescini, S. (2012b). Social referencing in dog-owner dyads? Anim. Cogn. 15, 175-185. doi: 10.1007/s10071-011-0443-0

Mertens, C., and Turner, D. C. (1988). Experimental analysis of human-cat interactions during first encounters. Anthrozoös 2, 83-97. doi: 10.2752/ 089279389787058109

Met, A., Miklósi, Á, and Lakatos, G. (2014). Gaze-following behind barriers in domestic dogs. Anim. Cogn. 17:1401. doi: 10.1007/s10071-014-0754-z

Miklosi, A., Pongracz, P., Lakatos, G., Topal, J., and Csanyi, V. (2005). A comparative study of the use of visual communicative signals in interactions between dogs (Canis familiaris) and humans and cats (Felis catus) and humans. J. Comp. Psychol. 119, 179-186. doi: 10.1037/0735-7036.119.2.179

Nagasawa, M., Kikusui, T., Onaka, T., and Ohta, M. (2009). Dog's gaze at its owner increases owner's urinary oxytocin during social interaction. Horm. Behav. 55, 434-441. doi: 10.1016/j.yhbeh.2008.12.002

Nagasawa, M., Mitsui, S., En, S., Ohtani, N., Ohta, M., and Sakuma, Y. (2015). Oxytocin-gaze positive loop and the coevolution of human-dog bonds. Science 348, 333-336. doi: 10.1126/science.1261022

Nagasawa, M., Mogi, K., Ohtsuki, H., and Kikusui, T. (2020). Familiarity with humans affect dogs' tendencies to follow human majority groups. Sci. Rep. 10:7119.

Nagasawa, M., Murai, K., Mogi, K., and Kikusui, T. (2011). Dogs can discriminate human smiling faces from blank expressions. Anim. Cogn. 14, 525-533. doi: 10.1007/s10071-011-0386-5

Nagasawa, M., Okabe, S., Mogi, K., and Kikusui, T. (2012). Oxytocin and mutual communication in mother-infant bonding. Front. Hum. Neurosci. 6:31. doi: $10.3389 /$ fnhum.2012.00031

Nicastro, N. (2004). Perceptual and acoustic evidence for species-level differences in meow vocalizations by domestic cats (Felis catus) and African wild cats (Felis silvestris lybica). J. Comp. Psychol. 118:287. doi: 10.1037/0735-7036.118.3.287

Ohkita, M., Nagasawa, M., Kazutaka, M., and Kikusui, T. (2016). Owners' direct gazes increase dogs' attention-getting behaviors. Behav. Process. 125:96. doi: 10.1016/j.beproc.2016.02.013

Pongrácz, P., Szapu, J. S., and Faragó, T. (2019). Cats (Felis silvestris catus) read human gaze for referential information. Intelligence 74, 43-52. doi: 10.1016/j. intell.2018.11.001

Potter, A., and Mills, D. S. (2015). Domestic cats (Felis silvestris catus) do not show signs of secure attachment to their owners. PLoS One 10:e0135109.doi: 10.1371/journal.pone.0135109

Quaranta, A., d'Ingeo, S., Amoruso, R., and Siniscalchi, M. (2020). Emotion recognition in cats. Animals 10:E1107.

Rieger, G., and Turner, D. C. (1999). How depressive moods affect the behavior of singly living persons toward their cats. Anthrozoös 12, 224-233. doi: 10.2752/ 089279399787000066

Saito, A., and Shinozuka, K. (2013). Vocal recognition of owners by domestic cats (Felis catus). Anim. Cogn. 16, 685-690. doi: 10.1007/s10071-013-0620-4

Schwab, C., and Huber, L. (2006). Obey or not obey? Dogs (Canis familiaris) behave differently in response to attentional states of their owners. J. Comp. Psychol. 120:169.

Siniscalchi, M., d'Ingeo, S., and Quaranta, A. (2016). The dog nose "KNOWS" fear: asymmetric nostril use during sniffing at canine and human emotional stimuli. Behav. Brain Res. 304:34.

Takagi, S., Arahori, M., Chijiiwa, H., Saito, A., Kuroshima, H., and Fujita, A. (2019). Cats match voice and face: cross-modal representation of humans in cats (Felis catus). Anim. Cogn. 22, 901-906.

Téglás, E., Gergely, A., Kupán, K., Miklósi, Á, and Topál, J. (2012). Dogs’ gaze following is tuned to human communicative signals. Curr. Biol. 22:209. 
Topal, J., Miklosi, A., Csanyi, V., and Doka, A. (1998). Attachment behavior in dogs (Canis familiaris): a new application of Ainsworth's (1969) strange situation test. J. Comp. Psychol. 112, 219-229.

Turcsán, B., Szánthó, F., Miklósi, Á, and Kubinyi, Á (2015). Fetching what the owner prefers? Dogs recognize disgust and happiness in human behaviour. Anim. Cogn. 18:83.

Turner, D. C., and Rieger, G. (2001). Singly living people and their cats: a study of human mood and subsequent behavior. Anthrozoös 14, 38-46.

Ueda, S., Kumagai, G., Otaki, Y., Yamaguchi, S., and Kohshima, S. (2014). A comparison of facial color pattern and gazing behavior in canid species suggests gaze communication in gray wolves (Canis lupus). PLoS One 9:e98217. doi: 10.1371/journal.pone.0098217

Vigne, J. D., Guilaine, J., Debue, K., Haye, L., and Gerard, P. (2004). Early taming of the cat in Cyprus. Science 304:259.
Yeon, S. C., Kim, Y. K., Park, S. J., Lee, S. S., Lee, S. Y., and Suh, S. Y. (2011). Differences between vocalization evoked by social stimuli in feral cats and house cats. Behav. Process. 87:183.

Conflict of Interest: The authors declare that the research was conducted in the absence of any commercial or financial relationships that could be construed as a potential conflict of interest.

Copyright (c) 2020 Koyasu, Kikusui, Takagi and Nagasawa. This is an open-access article distributed under the terms of the Creative Commons Attribution License (CC BY). The use, distribution or reproduction in other forums is permitted, provided the original author(s) and the copyright owner(s) are credited and that the original publication in this journal is cited, in accordance with accepted academic practice. No use, distribution or reproduction is permitted which does not comply with these terms. 